\title{
POR QUE HÁ CULTURA MATERIAL AO INVÉS DE NADA? UMA QUESTÃO ESQUECIDA DA ARQUEOLOGIA*
}

\author{
Hakan Karlsson**
}

\begin{abstract}
O objetivo deste ensaio é elucidar e discutir uma questão ontológica e fundamental que parece ter sido esquecida e simplificada nos discursos da Arqueologia contemporânea. Esta questão é Por que há cultura material em vez de nada? Em conformidade com este objetivo, e a questão colocada em evidência, este trabalho é completamente filosófico em sua natureza. Ele apresenta uma discussão que é provavelmente desconhecida, para a maior parte dos arqueólogos. Apesar deste fato, eu encorajaria o leitor a continuar, por que esta discussão leva a questões que são de crucial relevância para arqueólogos e a Arqueologia.

Independente de qual abordagem teórica escolhemos, podemos facilmente concordar que a cultura material do passado que lidamos como arqueólogos existe em frente de nossos olhos, mas: o que sabemos de sua Existência? Por Existência, e este é um ponto central, não quero dizer a visibilidade ou aparência do fenômeno. Em conformidade com os últimos argumentos do filósofo alemão Martin Heidegger, antes refiro-me à Existência como o processo que faz tudo que é manifesto, que o faz aparecer. Esta Existência que faz possível, e determina tudo o que é (Heidegger 1927:2-15, 1953: 14s., 1954b:16s., 85,106, 137-149, 1957:57ss.). Este argumento referente às diferenças ontológicas entre Existência e existências é provavelmente desconhecido para a maioria dos arqueólogos, por que nós normalmente referimonos à Existência da cultura material como o que é manifesto em uma maneira física. Ela existe na nossa frente, está presente perante nossos olhos, e pode ser ex-
\end{abstract}

(*) Tradução de Solange Nunes de Oliveira, mestranda em História, Unicamp, e Dione da Rocha Bandeira, arqueóloga do Museu Arqueológico de Sambaqui de Joinville, doutoranda em História, Unicamp. Revisão de Pedro Paulo A. Funari e Maria Isabel D'Agostino Fleming. $(* *)$ Departamento de Arqueologia da Universidade de Göteborg, Göteborg, Suécia. perimentada. Nós não distinguimos entre Existência e existências. Como então nós concebemos a Existência do megalito mostrado na ilustração a seguir? E como nós concebemos a Existência da ilustração em si? Pelo fato de serem visíveis e manifestos ou pelo processo que os faz manifestos?

\section{Ontologia tradicional}

Provavelmente a maioria de nós concebe a Existência, tanto do megalito como da ilustração, de acordo com a primeira proposta isto é, pelo que é manifesto em uma maneira física. Nós, então, abordamos a Existência destas existências da mesma maneira como os filósofos tradicionais póssocráticos, aristotélicos e platônicos. $\mathrm{E}$, ao mesmo tempo, não estamos cientes da Existência como o processo que faz o fenômeno manifesto. Nesta abordagem tradicional, a Existência como processo torna-se somente a aparência visível do fenômeno, em vez do processo crucial que o faz aparecer, isto é, não há conhecimento da diferença ontológica entre Existência e existência.

Esta visão tradicional da Existência tem estado conosco desde Platão e Aristóteles, e foi mais adiante desenvolvido e fortalecido, por exemplo, por Descartes e Kant. Platão interpreta a Existência como a idéia, como aquilo que é percebido no visível, os aspectos que são oferecidos pelo fenômeno em sua presença (Platão 1935a, 1935b). Assim, Platão deixa as consequiências da Existência (o aparecimento e a presença de existência) substituir a Existência como processo, e Existência e existências são consideradas como idênticas. A última conseqüência do desconhecimento da Existência como o processo de aparecimento é que a diferença (ontológica) entre Existência e existências é esquecida. A Existência é interpretada por Platão e seus sucessores como a aparência visível do fenômeno, enquanto a percepção subjetiva do fe- 


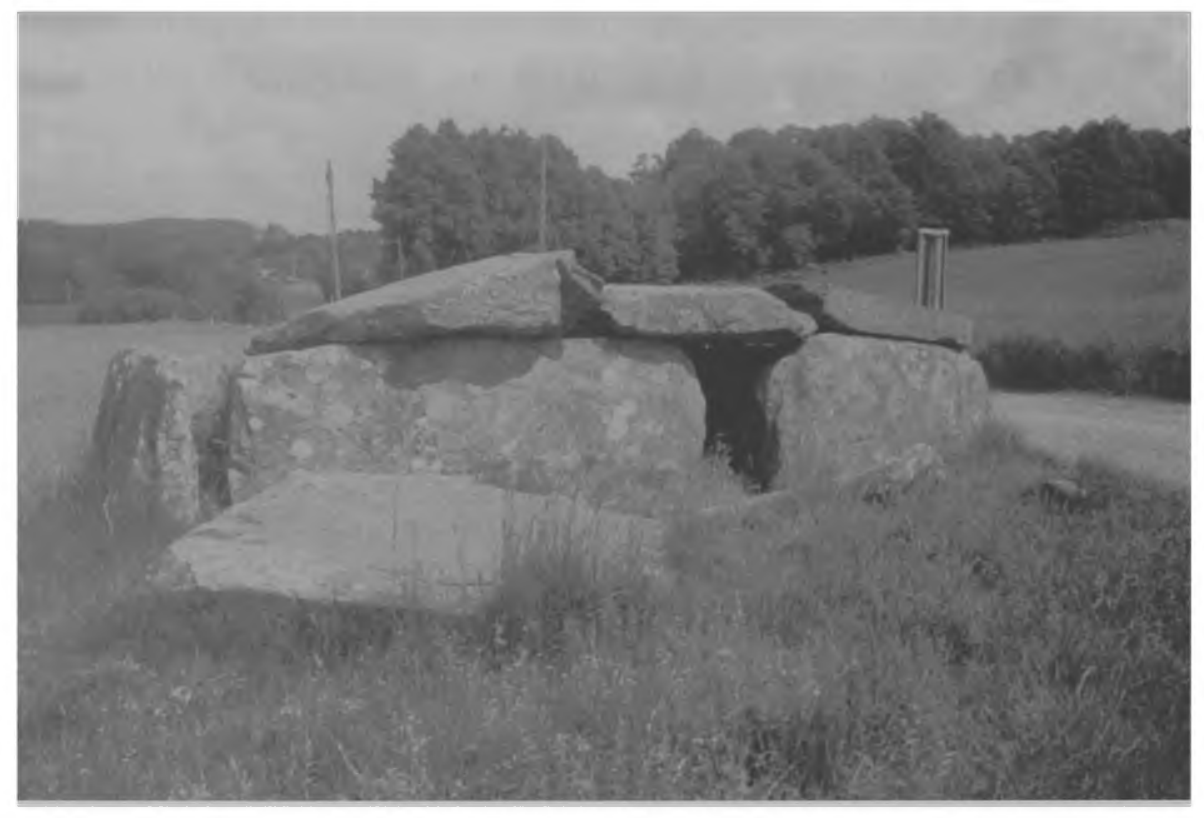

Ilustração-O megalito chamado "A Casa dos Anões", paróquia de Lindome, Halland, Suécia.

nômeno presente torna-se central. $\mathrm{A}$ idéia torna-se um paradigma (ideal), e a aparência de um fenômeno é considerada a emergência de uma cópia que pode ser julgada em conformidade com o ideal . A aparência de algo é, de agora em diante, uma aparência visível em conformidade com um ideal focalizado na consciência humana. Isto leva à divisão do mundo em sujeito e objeto, em pensamento (consciência) e objeto (da consciência), isto é, uma divisão entre pensamento humano e Existência como processo. Dentro desta estrutura, o sujeito humano e sua consciência são concebidos como uma entidade de pensamento que produz idéias representacionais do mundo no qual ele existe, que significa que o mundo se torna centrado no sujeito e sua produção de idéias. Nós todos conhecemos as conseqüências desta ontologia antropocêntrica, que chega a nós, principalmente, através dos argumentos de Descartes e Kant: a objetivação e uso das existências humanas e animais, a visão da verdade como correspondência entre idéias subjetivas e a percepção subjetiva dos objetos, a tentativa de achar verdades mensuráveis, seguras que se desenvolvem por meio do projeto moderno, e o esforço para o controle humano, razão, lógica e dominação. Em conformidade com isto, a metafísica ou ontologia tradicional é antropocêntrica em sua natureza, por que considera a produção humana de idéias como sendo o centro do mundo. Isto não significa que toda metafísica tradicional seja idealista em sua natureza, mas antes que as tradições de idealismo e realismo discutem somente o status ontológico das existências, enquanto elas têm em comum o fato que não reconhecem a unidade entre Existência e pensamento humano que precede qualquer distinção entre sujeito e objeto. De uma maneira simplificada, pode ser declarado que a principal razão para este antropocentrismo é encontrada no desconhecimento da diferença ontológica e a unidade entre Existência (como História) e pensamento humano (Heidegger 1947: 5-52, 1953:79s., 91, 137ss., 1954b:133ss., 1969: 66ss.). Há uma alternativa. É possível supor da Existência do megalito na ilustração e a Existência desta ilustração, não pelo fato que elas são visíveis e manifestas, mas em conformidade com a segunda proposta, pelo processo que as faz manifestas?

\section{Ontologia pré-socrática (heideggeriana tardia/recente)}

De acordo com os últimos argumentos de Martin Heidegger, os filósofos pré-socráticos, tais como Parmênides e Heráclito, não trabalharam dentro da estrutura de um esquecimento da diferença 
KARLSSON, H. Por que há cultura material ao invés de nada? Uma questão esquecida da Arqueologia. Rev. do Museu de Arqueologia e Etnologia, São Paulo, Suplemento 3: 21-29, 1999.

ontológica nem negligenciaram a Existência como o princípio último para tudo que é manifesto. Eles não conceberam o relacionamento entre existência humana e Existência como contraditórias; antes, viam a capacidade humana para pensar como uma resposta à Existência (como História). Existência foi, por isso, concebida como o último grau para tudo que é, incluindo nossa existência humana (Heidegger 1953: 104-111, 1954b:175, 1957: 14ff.). ${ }^{1}$ Assim, os argumentos pré-socráticos são anulados se comparados com os pós-socráticos. Mas o que isto implica? Nós somos seres humanos, e nosso pensamento é determinado pela Existência (como história)?

De acordo com Heidegger, a Existência é responsável pelo crucial convite a pensar sobre isso em primeiro lugar. Assim, nosso pensamento é ainda uma atividade que sucede em nossa consciência, mas nossa consciência (ou nossa capacidade de pensar) é baseada na Existência. Pensamento, então, não é uma questão da produção de idéias representacionais, mas antes a abertura para aquilo que nos chama a pensar, uma abertura na qual nós deixamos a verdade da Existência aparecer contra as condições de sua própria iniciativa. Neste contexto, a verdade não é concebida, como correspondência, mas como abertura (aletheia) (Heidegger 1947:54-57, 1954b: 33ss., 84ss., 147ss., 1959: 19s., 1962: 39s.). Isto significa - sem dúvida estranhamente para a maioria de nós - que não somos nós que indicamos as coisas, mas antes as coisas que se mostram para nós no evento em que a Existência, como processo, deixa-as serem vistas por nós. Consequientemente, nós podemos ter diferentes opiniões concernentes a um fenômeno específico, mas é a Existência, como processo, que é a razão última para o fato que há uma existência real sobre a qual podemos tecer opiniões (ibid.) Por exemplo, nós podemos interpretar o megalito atual como "A Casa dos Anões", em conformidade com a visão do século XVII, ou nós podemos interpretá-lo como uma sepultura. E podemos interpretar a ilustração como um reflexo da realidade empírica ou como várias impressões sombrias em um ensaio. $O$ ponto é que, tanto o megalito quanto a ilustração (ainda) existem. Estes argumentos insinuam que a Existência, quando revelada pelo nos-

(1) Nestes argumentos, Heidegger refere-se, primeiro de tudo, a Parmênides, fragmentos números 5 e 6 (Parmênides 1951). so pensamento, é em parte idêntica, ou melhor unida, com a natureza e atividade de pensamento. A relação entre a Existência e o pensamento das existências humanas é dependência mútua, na qual nós, como existência humana, "residimos" na Existência. Isto é por que a Existência precisa de nosso pensamento como uma abertura, a partir da qual pode surgir, ao mesmo tempo que nós precisamos da abertura da Existência (Heidegger 1947:111s., 1953: 75s., 1954 a: 187-204, 1954b: 4s., 33, 146ss., 158, 1957: 18s., 23-41, 1959: 49ss.).

Mas como é possível que a existência humana possa ser conduzida em direção à Existência e, ao mesmo tempo, recebe a revelação de seu próprio motivo? Heidegger declara que nosso requerimento de verdade é a base para a relação entre nós e as coisas, e que esta relação ocorre como História (Heidegger 1957: 64, 1959: 56ss., 1961: 481ss., 489). Aqui, a História é concebida como um modo de conhecimento e não como os acontecimentos e ações do mundo ou como as realizações culturais de existências humanas. A coisa fundamental na História não é a sua natureza seqüencial, mas antes, o pensamento histórico. Nós deveríamos olhar para a História onde a articulação das coisas ocorre. Tal História relaciona os seres humanos às coisas porque, por meio dessa relação, as coisas sustentam-se pela exigência humana que se tornem verdadeiras (não escondidas), ao mesmo tempo que esta exigência de verdade significa que a existência seja explicitada. Assim, a articulação da natureza das coisas, é um aspecto de revelação (verdade) da Existência, como processo. Mas, como já mencionado, o pensamento humano e nossa possibilidade de articular a natureza das coisas é ao mesmo tempo baseado na Existência como processo. Assim, a Existência como processo é a fonte e a origem de toda articulação e todo o pensamento, e por isso também a fonte e origem da História. De uma maneira simplificada, pode ser realçado que a Existência é a História. (Heidegger 1947:81, 1954a: 277, 1969: 1-26, 1988: 494).

Estes raciocínios implicam que a Existência (como História) é a origem de todas as espécies de pensamentos sobre a Existência das existências? É a Existência um fundamento para as idéias présocráticas e pós-socráticas da Existência? De acordo com Heidegger esta é exatamente a base como ela é. A Existência tem uma História (em uma interpretação mais tradicional do conceito) que é baseada em diferentes articulações históricas (idéias) 
KARLSSON, H. Por que há cultura material ao invés de nada? Uma questão esquecida da Arqueologia. Rev. do Museu de Arqueologia e Etnologia, São Paulo, Suplemento 3: 21-29, 1999.

da Existência (Heidegger, 1950: 311ss., 1953: 70, 143, 1957: 55ss., 1959: 56ss., 1969: 1-26, 1975). Mas o ponto é que Heidegger pensa que a Existência como processo (em si) é dinâmica em sua natureza. Por isso, nossas articulações históricas de Existência (baseadas em nossas estruturas transcendentais de experiência, isto é, nosso pré-entendimento) não são a base para esta História, antes, nossos pensamentos são somente abertura pela qual a Existência se manifesta em diferentes aspectos de diferentes épocas históricas. Portanto, tanto nosso entendimento quanto nosso pré-entendimento são baseados na Existência (como História) e não em nossa estrutura transcendental (antropocêntrica) de experiência.

Mas esses raciocínios não concernentes à dinâmica de Existência (como História) criam uma existência humana passiva, totalmente determinada pela Existência e que não pode influenciar a História? A questão crucial é: temos algum tipo de liberdade dentro dessas estruturas? Heidegger acentua que não podemos influenciar o retorno da Existência e que não conhecemos quando este retorno virá ou mesmo se ele virá (Heidegger 1962: 37-47).

Mas, ao mesmo tempo, nós ainda temos a possibilidade de deixar as existências serem o que elas são. Temos a liberdade de permitir outros a tornarem-se o que eles são e aceitar nossa dependência mútua. Nós também temos a possibilidade de propor questões fundamentais sobre Existência (como História) e o relacionamento entre nós mesmos e a Existência (como História). Nós podemos preparar nós mesmos para o retorno da Existência (Heidegger 1943: 16ss., 1953:16-24, 29s., 120s., 124ss., 1962: 37-47). De meu ponto de vista, este projeto, em direção às estruturas fundamentais de nossa existência, é o oposto da passividade.

Destes raciocínios, se compreende que a questão presente (Por que há cultura material em vez de nada?) deve ser, satisfatoriamente, respondida. "Por que a Existência (como História) permite-nos aparecer através de nossos pensamentos".

\section{Arqueologia (pós-socrática) contemporânea}

Estes raciocínios são de alguma relevância para a Arqueologia, uma disciplina, e para nós, como arqueólogos? Acredito que eles são relevantes e importantes. Isto é principalmente porque as abordagens arqueológicas dominantes, contemporâneas, ocidentais (histórico-cultural, funcionalista,
Marxista, processual e pós-processual) e as diferentes abordagens que podem ser classificadas com estes títulos simplificados, parecem estar mais ancoradas no antropocentrismo pós-socrático. Por exemplo, é óbvio que tanto o processualismo quanto o pós-processualismo concebem a Existência dos vestígios pelo fato de serem visíveis e manifestos, e não como o processo que os faz, manifestos. Este significado que atribuímos aos vestígios do passado é concebido através de uma construção sócioideológica do presente ou como um produto da metodologia científica. Assim, tanto o processualismo quanto o pós-processualismo trabalham dentro de uma estrutura da metafísica pós-socrática. Isto significa que qualquer destas abordagens que usemos, estaremos concentrando nas existências (coisas/artefatos) como existências, enquanto permanece irrefletido de Existência (como história), isto é, o processo ou maneira pela qual tudo que é vem em direção aos nossos pensamentos. Em outras, palavras, não sabemos da diferença (ontológica) entre existência e Existência, nem sabemos da unidade entre o nosso pensamento e Existência (como História). Isto significa que tanto o processualismo quanto o pós-processualismo somente tratam de questões de vestígios do passado e nunca respondem às questões que emanam da Existência destas existências. Este é o caso, se argumentarmos de uma posição onde nossas idéias (independentemente produzidas em nossa consciência) podem ser testadas e analisadas de uma maneira metodológica em contraposição à realidade material ou se alegamos que nosso contexto sócio-político forma nossas idéias e assim o significado do mundo material. Este contexto é ainda considerado como construído somente como consequiência de nossa subjetividade humana, e assim, indiretamente, pela nossa consciência humana. Pode ser ainda dito que as similaridades primárias entre o processualismo e o pós-processualismo consistam no fato que partidários deste ponto de vista somente argumentam sobre o status ontológico das existências, enquanto eles têm em comum o fato que não reconhecem a unidade entre Existência e pensamento humano que precede qualquer distinção entre sujeito e objeto.

Supérfluo dizer que a dicotomia entre sujeito e objeto não pode ser desconstruída dentro da estrutura destes raciocínios antropocêntricos, nem pode o sujeito tornar-se descentrado. $O$ processualismo enfoca a realidade do passado que nós, como seres humanos pensantes (de forma independente 
KARLSSON, H. Por que há cultura material ao invés de nada? Uma questão esquecida da Arqueologia. Rev. do Museu de Arqueologia e Etnologia, São Paulo, Suplemento 3: 21-29, 1999.

e isolada), decodificamos com metodologias objetivas, e o pós-processualismo concentra-se sobre a construção subjetiva do passado que toma o lugar em nossa consciência. Assim, a dicotomia entre sujeito e objeto é inalterada em ambas as abordagens, e a concentração antropocêntrica sobre a consciência humana não pode ser desconstruída, porque estas abordagens não reconhecem a diferença ontológica e a unidade entre Existência (como história) e o pensamento humano. Pode ser também enfatizado que as existências, tal como os vestígios do passado, são tratadas como uma forma de postura de reserva que está sempre à disposição de nosso desejo subjetivo. Este é o caso se os estabelecemos como objetos independentes ou como construções subjetivas. ${ }^{2}$ Disto, segue-se que, dentro da estrutura do antropocentrismo, arqueólogos parecem usar o passado e sua cultura material somente como uma forma de postura de reserva, que nós podemos manipular em conformidade com nossa vontade e nossos desejos etc.. Em outras palavras, o desconhecimento da diferença ontológica e o poder crucial da Existência (como História) no processualismo e no pós-processualismo, implica que estas abordagens são incluídas dentro da mesma estrutura pós-socrática, metafísica.

Para muitos de nós, a questão proposta, e a sua discussão apresentada acima, parece ser completamente irrelevante: existem os objetos de cultura material (megalíticos e ilustrações) porque podemos vê-los, tocá-los ou usá-los em conformidade com nossos projetos ideológicos ou existenciais. A questão crucial antes parece ser como o seu significado é considerado, como uma construção do passado ou como uma construção do presente?É claro, não nego, as diferenças epistemológicas entre processualismo e pós-processualismo concernentes a estas questões; o ponto é que as questões concernentes ao significado da cultura material são secundárias em comparação com a questão esquecida que adiantei acima. ${ }^{3}$ A questão se o atual megalito é "A Casa dos

(2) Para estes pontos de vista processual e pós-processual, ver por exemplo, os ângulos de Binford, Hodder, Shanks, Tilley, etc. (3) Para uma discussão mais compreensiva da fundação metafísica comum do processualismo e pós-processualismo, ver Karlsson (no prelo), para as discussões das diferenças epistemológicas entre processualismo e pós-processualismo ver, por exemplo, Binford 1982a, 1982b, 1987, 1989a, 1989b; Hodder 1986, 1991; Earle \& Preucel 1987; Shanks \& Tilley 1987a, 1987b; Tilley 1990; Shanks 1992 e Thomas 1996.
Anões" ou se é uma sepultura, é secundário, bem como a questão se as ilustrações são algumas impressões sombrias em artigo ou um reflexo da realidade empírica. Este será o caso, na medida em que não tentarmos responder à questão básica de porquê esses fenômenos ocorrem.

Disto, segue que a Arqueologia Contemporânea, ou melhor os arqueólogos contemporâneos, não estão conscientes de, e não usam, o potencial existencial inerente a Existência, enquanto muitos de nós parecem ter hesitado no beco sem saída da metafísica pós-socrática, isto é, nas dicotomias entre sujeito e objeto e no antropocentrismo.

\section{Uma (recente) abordagem (arqueológica contemplativa) heiddegeriana}

Tendo tentado espalhar alguma luz nas complexidades do raciocínio tardio heideggeriano, agora gostaria de considerar como tais ângulos podem influenciar, enriquecer, nossa prática arqueológica. Supérfluo dizer, a discussão abaixo é somente um resumo iluminando alguns temas relevantes desta complexa questão, e é conveniente enfatizar que as estruturas destes temas estão simplificadas, pois elas são inseparavelmente intrelaçadas umas nas outras. ${ }^{4}$

\section{$O$ desconhecimento de nossa "habitação" na Existência (como História)}

Uma Arqueologia contemplativa inspirada pelos ângulos tardios heideggerianos poderia enriquecer a Arqueologia primeiramente porque, de uma maneira auto-reflexiva, ela leva arqueólogos a entender a fundação profunda de nossa existência humana e nosso pensamento humano. Leva arqueólogos a tornarem-se cientes da diferença ontológica e a unidade entre Existência e existências, isto é, entre Existência (como História) e nosso pensamento humano. Em outras palavras, esta $\mathrm{Ar}$ queologia vai em direção à questão do pensamento, isto é, ela pensa sobre o pensamento e é revelada em relação à Existência, e a leva a aparecer contra

(4) Para minhas discussões de uma Arqueologia contemplativa, ver também Karlsson 1997a, 1987b, 1998, Karlsson (no prelo). 
KARLSSON, H. Por que há cultura material ao invés de nada? Uma questão esquecida da Arqueologia. Rev. do Museu de Arqueologia e Etnologia, São Paulo, Suplemento 3: 21-29, 1999.

a experiência de sua própria iniciativa. Ao mesmo tempo, segue um meio caminho, onde nós precisamos da Existência das existências ao mesmo tempo que a Existência da existência precisa de nós, ou melhor, de nosso pensamento.

\section{Desconstrução das metafísicas (pós-socráticas)}

Em uma Arqueologia contemplativa, a Existência não é conseguida como uma parte passiva da existência ou como uma idéia subjetiva de existência. A Existência é, antes, aquilo que nos chama a pensar. Por meio do desconhecimento, de nossa "habitação" na Existência, esta abordagem dá-nos a habilidade para mover-nos além da visão da Existência tradicional, pós-socrática, das dicotomias secundárias entre idealismo e realismo, construtivismo e objetivismo, sujeito e objeto, presente e passado, e descentrar o antropocentrismo pós-socrático (isto é, a divisão entre a Existência e o pensamento humano), sem inclinação em direção a estas dicotomias tradicionais. Esta abordagem prepara-nos para admitir que estas dicotomias são secundárias em relação ao fato que Existência (como História) é a origem primária de nossa temporalidade e nosso pensamento, bem como a última fundação para o aparecimento da Existência em nossos pensamentos, em nossa faculdade de fala, isto é, a fundação para tudo que é (existe). Em tal abordagem, se está ciente da diferença (ontológica) e a unidade da Existência e existências, bem como do poder da Existência (como História), em outras palavras, do fato que nossa "habitação" na Existência precede todas as formas de dicotomia póssocrática, bem como antropocentrismo pós-socrático. Isto significa que uma Arqueologia contemplativa também transcende as visões tradicionais e pós-socráticas de conceitos tais como verdade, lógica e significado. Verdade e significado não são mais concebidos como a existência produzida, somente como uma consequência das idéias e ideais que residem e são produzidas na consciência humana, e a correspondência entre estes ideais e várias existências objetivadas. Verdade e significado são melhor concebidos como o aparecimento da Existência do pensamento humano. A lógica é desconstruída como um instrumento para o julgamento de pensamentos corretos ou incorretos, como uma consequiência do fato que o pensamento não é mais (quanto à inconsciência) dividido do Ser. Na Arqueologia contemplativa, pensamento, Existência (como logos) e verdade (aletheia) são re-reunidos. Assim, a atual desconstrução é dirigida nos pontos de vista idealista e realista e em vários pontos de vista processual e pós-processual na Arqueologia contemporânea. A principal intenção desta descontrução é acentuar a diferença ontológica e o atual relacionamento e unidade entre Existência e existências, isto é, acentuar que a Existência (como História) é a fundação esquecida de toda a forma de pensamento, uma fundação que precede toda a interpretação ontológica das existências.

\section{Outra visão das existências}

Uma Arqueologia contemplativa, que deixa os seres existirem, deve incluir uma atitude respeitosa, em direção a outras existências (na forma de coisas ou artefatos), quando a concebemos como uma condição reservada que existe simplesmente para nosso beneficio, prazer ou uso. A mais fantástica coisa sobre os artefatos passados e presentes não é o que eles são mas, antes, para o que eles são e por que eles têm a mesma origem que nós. Essas existências, ou melhor sua Existência, é que nos dá a estrutura de nossa orientação no mundo. Estas existências não podem somente ser interpretadas como objeto que permanece em uma relação dialética para um intérprete subjetivo, isto é, a Existência (como História) é o fundamento do arqueólogo e seus pensamentos, passados e presentes, sobre a cultura material. Assim, esta é também a fundação de nossa habilidade para atribuir significados dos passados para outras existências. Eu não rejeito a visão pós-processual do significado do passado como uma construção do presente. Minha questão é que esta construção é baseada na temporalidade de nós mesmos e de nossas existências (Existência como História) e não somente em nossas escolhas (ou no caso pós-processual contextualizado) subjetivas. Para entender estes aspectos, temos que compreender, que mesmo que a cultura material do passado e presente não produz qualquer significado final em si, ela ou melhor a sua Existência, é ainda, a origem do que os arqueólogos conhecem e fazem. Nós podemos atribuir diferentes significados para o fenômeno específico, tais como, o megalito, mas a questão principal é que isto é e 
que isto está ocupando nossos pensamentos. Se ele não existisse, seu significado não seria um problema para nós. Em conformidade com as discussões anteriores, estas observações têm que ser entendidas de uma maneira realista, porque esta Existência (como História) que é responsável pelo fato de que há artefatos, bem como pensamento humano, em vez de nada. Desnecessário dizer, a situação na qual a Existência deixa as existências emergirem através de nossos pensamentos é um entrelaçado entre pensamentos humanos e Existência.

Em outras palavras, a Existência precisa de nossa capacidade de pensar, e nossa "habitação" na Existência. Disto, pode ser argumentado que o interesse de uma Arqueologia contemplativa repousa, em primeiro lugar, no aparecimento da Existência de existências, por meio de nosso pensamento e de nossa faculdade de fala, e não controle metodológico, na busca por significados passados ou no presente, uso sócio-político de cultura material, isto é, o interesse é dirigido à verdade como aletheia e nossa "habitação" na Existência e verdade.

\section{Pluralismo teórico}

Eu quero sugerir que uma Arqueologia contemplativa volta-se às razões ontológicas sobre tudo que existe. Por meio dessa espécie de contemplação de nosso relacionamento para a Existência de existências, podemos obter um entendimento diferente das razões ontológicas para tudo que é, incluindo as razões para a nossa própria existência, nosso próprio pensamento. Esta Arqueologia contemplativa, então, é dirigida ao avanço da Existência, não somente nos artefatos, mas, também, nas reflexões teóricas e argumentos na Arqueologia. Ela presta atenção às razões para abordagens teóricas $\mathrm{e}$ diferentes interpretações, ao mesmo tempo como ela "deixa estas existências acontecerem" Tal Arqueologia concomitante alimenta o pluralismo teórico e guia à fundação última deste pluralismo. A Arqueologia contemplativa reflete sobre o pensamento e conhece e é ágil para discutir os pontos de vista antropocêntricos que parecem ser a base de toda a abordagem contemporânea, e teórica na Arqueologia. Isto é, principalmente, porque estes pontos de vista antropológicos são, ao mesmo tempo, num nível primário, baseados na Existência (como História). Conseqüentemente, esta discussão não é dirigida somente aos pontos de vista processual e pós-processual, mas a todos os outros pontos de vistas teóricos em Arqueologia. Meu propósito não é destruir estas abordagens e suas interpretações, mas, antes, discutir as razões fundamentais para elas.

\section{Preparação para o "retorno" da Existência}

Em seus últimos argumentos Heidegger enfatiza que deveríamos preparar o nosso pensamento para o "retorno" da Existência e que uma parte desta preparação é aprender a pensar de uma maneira contemplativa, isto é, pensar sobre o pensamento e sua fundação na Existência (como História). Heidegger também enfatiza que nós podemos influenciar o "retorno" da Existência e que não sabemos quando este "retorno" virá ou se ele virá (Heidegger 1962: 37-40, Stambaugh 1995: 209-212, Pöggeler 1996: 210-212). Estas idéias parecem criar um homem passivo totalmente controlado pela Existência (como História), mas deveríamos lembrar da dependência mútua entre o pensamento do homem e Existência. Nós temos também visto acima que podemos propor questões fundamentais sobre a Existência de existências e o relacionamento entre pensamento e a Existência das existências. Assim, ainda temos a liberdade para agir dentro da estrutura da Existência, podemos ainda permitir a outros tornarem-se o que eles são e aceitar nossa dependência mútua.

\section{Reflexão e crítica}

Uma Arqueologia contemplativa é um "caminho de preparação" que guia além do ancoradouro contemporâneo da Arqueologia na metafísica antropocêntrica, tradicional. Isto significa que esta espécie de Arqueologia está também pronta para refletir criticamente nas conseqüências do antropocentrismo. Por exemplo, a conexão de cálculo usa das existências como uma defesa e sua legitimação deste caminho à destruição é uma consequiência do desconhecido da diferença ontológica e o poder da Existência (como História). Isto significa que uma Arqueologia contemplativa é também dirigida às questões concernentes ao uso (ideológico) presente na existência, no nível geral, porque ela demonstra que este uso não é primeiramente baseado na subjetividade mas na Existência (como História). A Arqueologia contemplativa não evita as implicações políticas da Ar- 
queologia, ela, antes, empenha-se em enfatizar suas fundações. Uma das implicações disto é que a Arqueologia contemplativa é conectada com amplas séries de discursos existenciais e políticos, ao mesmo tempo é uma preparação para o "retorno" da Existência. Esta Arqueologia é auto-reflexiva em sua natureza, por que é ancorada a uma discussão das fundações últimas da nossa existência e nosso pensamento, bem como de suas identidades como arqueólogos e seres humanos. Dentro desta estrutura, estamos, constantemente, prontos para questionar as nossas "indisputáveis" doutrinas, bem como todas as outras doutrinas "indisputáveis". de onde quer que elas venham.

\section{A contemplação como "método"}

Uma Arqueologia contemplativa não faz qualquer reivindicação tradicional, científica, metodológica concernente à maneira de fazer as pessoas entenderem o significado original do passado e sua cultura material. Este pensamento sobre o pensamento e a consciência de nossa "habitação" na Existência (como História), que são os temas centrais de uma Arqueologia contemplativa podem ser concebidos como uma espécie de "método" um "método" que é dirigido à dimensão existencial de nossa vida presente como seres humanos e como arqueólogos e nas razões de nossa existência. Se reconhecemos que nosso pensamento é uma resposta ao chamado da Existência, deve, ao mesmo tempo, ser concebido como um "método" não antropocêntrico que revela tanto as existências quanto as fundações de tudo queé, istoé, Existência (como História). Por exemplo, pode ser enfatizado que, quando se volta para uma discussão das visões metafísicas contemporâneas nas quais baseamos nossa própria existência, o "método" contemplativo pode nos ajudar a refletir, criticamente, sobre a espécie de pensamento que decide como vemos outras existências e nós mesmos. Assim, há um momento de desconstrução do questionamento crítico unicamente em tal "método" contemplativo. Este caminho de contemplação guia-nos além da dicotomia pós-socrática entre sujeito e objeto, e além do antropocentrismo e sua divisão entre pensamento e Existência.

\section{Conclusão}

Até agora, nós arqueólogos, presos no antropocentrismo pós-socrático, temos argumentado somente sobre o status ontológico das existências, enquanto não temos reconhecido a diferença ontológica e a unidade entre Existência (como História) e pensamento humano que precede esta argumentação secundária. Nem temos sido cientes do fato que é a Existência (como História) que deixa os fenômenos (a cultura material) tornarem-se presentes para nós. Em conformidade com os argumentos esboçados acima, nosso relacionamento com a cultura material não poderia ser, primeiramente, concebido como um relacionamento dialético. Minha questão é que, mesmo se nos orientarmos no mundo com a ajuda da cultura material, o principal relacionamento entre nós como intérpretes arqueológicos, e a cultura material interpretada, está em nossa razão comum, nossa "habitação" na Existência (como na História), isto é, nos orientamos não tanto com a ajuda da cultura material como com a ajuda da Existência. Existência (como História) nos capacita tanto para as experiências quanto para construir as coisas. A Existência deixa-nos lidar com as existências e criar a História. Precisamos da Existência do megalito, e as ilustrações discutidas acima não existem somente porque alguém as construiu em conformidade com seu (pré) entendimento. Quando esta Existência, que é a última razão de nosso (pré) entendimento de um fenômeno, inclui o (pré) entendimento de nossa própria existência como pessoas e como arqueólogos.

Muitos podem alegar que a discussão e as propostas apresentadas neste texto são baseadas em uma construção teórica ou, precisamente, em uma fabricação lingüística, concernente à diferença ontológica entre Existência e existência. $O$ que é Existência se não o fato que as existências são manifestas, o fundamento que torna tudo que é manifesto e que determina tudo que existe? Neste contexto, poderia guiar o leitor perdido a tentar responder a esta questão, mas vamos, pelo menos, começar a abordá-la através da questão crucial: Por que a cultura material, em vez de nada? Eu existo, você é, o megalito na ilustração existe e a ilustração existe, mas por quê ?

\section{Agradecimentos}

Gostaria de agradecer ao Professor Funari por me convidar para publicar este artigo. Agradecimentos vão também para Anna Carin Andersson, Per Cornell e Ola W. Jensen pelos comentários, em uma primeira versão deste artigo, e para Neil Tornkinson pela revisão da linguagem. 
KARLSSON, H. Por que há cultura material ao invés de nada? Uma questão esquecida da Arqueologia. Rev. do Museu de Arqueologia e Etnologia, São Paulo, Suplemento 3: 21-29, 1999.

\section{Referências bibliográficas}

BINFORD, L.R.

1982a Meaning, Inference and the Material Record. C. Renfrew; S. Shennan (Eds.) Ranking, Resource and Exchange. Cambridge, Cambridge University Press: 160-163.

1982b Objectivity-Explanation-Archaeology-1981. C. Renfrew; M.J. Rowlands; B.A. Segraves (Eds.) Theory and Explanation in Archaeology. New York and London, Academic Press: 125-138.

1987 Data, Relativism and Archaeological Science. Man (N.S.), 22: 391-404.

1989a Review of Hodder, Reading the Past: Current Approaches to Interpretation in Archaeology. L.R. Binford (Ed.) Debating Archaeology. San Diego, Academic Press: 69-71.

1989b Science or Seance, or Processual to 'Post-processual' Archaeology. L.R. Binford (Ed.) Debating Archaeology. San Diego, Academic Press: 27-40.

EARLE, T.K.; PREUCEL, R.W.

1987 Processual archaeology and the radical critique. Current Anthropology, 28: 501-538.

\section{HEIDEGGER, $M$.}

1927 Sein und Zeit, Erste Hälfte. Jahrbuch für Philosophie und phänomenologische Forschung, Halle, VIII: 1-438.

1943 Vom Wesen der Wahrheit. Frankfurt: Klostermann.

1947 Platons Lehre von der Wahrheit: Mit einem Brief über den "Humanismus". Bern: Francke.

1950 Holzwege. Frankfurt: Klostermann.

1953 Einfuihrung in die Metaphysik. Tübingen: Niemeyer.

1954a Vorträge und Aufsätze. Pfullingen: Neske.

1954b Was heißt Denken?. Tübingen: Niemeyer.

1957 Identität und Differenz. Pfullingen: Neske.

1959 Gelassenheit. Pfullingen: Neske.

1961 Nietzsche, Erster Band. Pfullingen: Neske.

1962 Die Technik und die Kehre. Pfullingen: Neske.

1969 Zur Sache des Denkens. Tübingen: Niemeyer.

1975 Die Grundprobleme der Phänomenologie. Gesamtausgabe, 24. Frankfurt: Klostermann.

1989 Beiträge zur Philosophie (Vom Ereignis). Gesamtausgabe, 65. Frankfurt: Klostermann.

\section{HODDER, I.}

1986 Reading the Past: Current Approaches to Interpretation in Archaeology. Cambridge: Cambridge University Press.

1991 Interpretative Archaeology and its Role. American Antiquity, 56: 7-18.

\section{KARLSSON, $\mathrm{H}$.}

1997a Anthropocentrism Revisited: A Contemplative Archaeological Critique. Archaeological Dialogues, 4 (1): 114-119. (in press)

1997b Being and Post-processual Archaeological Thinking: Reflections upon Post-processual Archaeologies and Anthropocentrism. Gotarc Serie C, Arkeologiska Skrifter 15. Göteborg.

1998 Re-Thinking Archaeology. Gotarc Series B, Gothenburg Archaeological Theses 8. Göteborg. Brothers in arms and beyond the secondary front. A contemplation upon the common metaphysical foundation of processual and post-processual archaeologies. A.C. Andersson et al. (Eds.) The Kaleidoscopic Past: Proceedings of the Fifth Nordic-TAG Conference, Göteborg, 2-5 April 1997. GOTARC Serie C, Arkeologiska Skrifter

PARMENIDES 16, Göteborg.

(1951) Fragmente. H. Diels (Ed.) Die Fragmente der Vorsokratiker. Berlin, Weidmannsche: 227-246.

\section{PLATO}

(1935a) Republic VI. English translation by Shorey, P. Plato, The Republic. London, Heinemann: 3-117.

(1935b) Republic VII. English translation by Shorey, P. Plato, The Republic. London, Heinemann: 119-233.

PÖGGELER, 0

1996 Does the saving power also grow? C. Macann (Ed.) Critical Heidegger. London, Routledge: 206-226.

SHANKS, $M$.

1992 Experiencing the Past: On the Character of Archaeology. London: Routledge.

SHANKS, M.; TILLEY, C.

1987a Re-Constructing Archaeology: Theory and Practice. Cambridge: Cambridge University Press.

1987b Social Theory and Archaeology. Cambridge: Polity Press.

STAMBAUGH, $\mathbf{J}$.

1995 The Turn. B.E. Babich (Ed.) From Phenomenology to Thought, Errancy and Desire. Dordrecht, Boston \& London, Kluwer Academic Publishers: 209-212.

THOMAS, J.

1996 Time, Culture \& Identity. London: Routledge. TILLEY, C.

1990 On Modemity and Archaeological Discourse. I. Bapty; T. Yates (Eds.)Archaeology after Structuralism: Post-structuralism and the Practice of Archaeology. London, Routledge: 127-152. 